\title{
Early speech development in Koolen de Vries syndrome limited by oral praxis and hypotonia
}

\author{
Angela T. Morgan $\mathbb{1}^{1,2,3} \cdot$ Leenke van Haaften ${ }^{4} \cdot$ Karen van Hulst ${ }^{4} \cdot$ Carol Edley $^{5} \cdot$ Cristina Mei $^{1} \cdot$ Tiong Yang Tan $^{6,7}$. \\ David Amor ${ }^{1,7}$. Simon E. Fisher ${ }^{8,9} \cdot$ David A. Koolen ${ }^{10}$
}

Received: 19 May 2017 / Revised: 10 October 2017 / Accepted: 17 October 2017 / Published online: 11 December 2017

(c) European Society of Human Genetics 2018

\begin{abstract}
Communication disorder is common in Koolen de Vries syndrome (KdVS), yet its specific symptomatology has not been examined, limiting prognostic counselling and application of targeted therapies. Here we examine the communication phenotype associated with KdVS. Twenty-nine participants (12 males, 4 with KANSL1 variants, 25 with 17q21.31 microdeletion), aged 1.0-27.0 years were assessed for oral-motor, speech, language, literacy, and social functioning. Early history included hypotonia and feeding difficulties. Speech and language development was delayed and atypical from onset of first words $(2 ; 5-3 ; 5$ years of age on average). Speech was characterised by apraxia (100\%) and dysarthria (93\%), with stuttering in some (17\%). Speech therapy and multi-modal communication (e.g., sign-language) was critical in preschool. Receptive and expressive language abilities were typically commensurate $(79 \%)$, both being severely affected relative to peers. Children were sociable with a desire to communicate, although some $(36 \%)$ had pragmatic impairments in domains, where higher-level language was required. A common phenotype was identified, including an overriding 'double hit' of oral hypotonia and apraxia in infancy and preschool, associated with severely delayed speech development. Remarkably however, speech prognosis was positive; apraxia resolved, and although dysarthria persisted, children were intelligible by mid-to-late childhood. In contrast, language and literacy deficits persisted, and pragmatic deficits were apparent. Children with KdVS require early, intensive, speech motor and language therapy, with targeted literacy and social language interventions as developmentally appropriate. Greater understanding of the linguistic phenotype may help unravel the relevance of KANSL1 to child speech and language development.
\end{abstract}

Electronic supplementary material The online version of this article (https://doi.org/10.1038/s41431-017-0035-9) contains supplementary material, which is available to authorised users.

\footnotetext{
$\triangle$ Angela T. Morgan

angela.morgan@mcri.edu.au

1 Murdoch Childrens Research Institute, Melbourne, Australia

2 Department of Speech Pathology and Audiology, University of Melbourne, Melbourne, Australia

3 Royal Children's Hospital, Melbourne, Australia

4 Donders Centre for Neuroscience, Department of Rehabilitation, Radboud University Medical Centre, Nijmegen, The Netherlands

5 Cook Children's Medical Centre, Fort Worth, TX, USA

6 Victorian Clinical Genetics Services, Murdoch Childrens Research
}

\section{Introduction}

Koolen de Vries syndrome (KdVS; MIM 610443) is a multi-system disorder caused by haploinsufficiency of KANSL1, either due to a $17 \mathrm{q} 21.31$ microdeletion or intragenic variant [1-4]. The prevalence is estimated at 1 in 130,000 to 1 in $20,000[2,5]$. Key phenotypic features include developmental delay, intellectual disability,

Institute, Melbourne, Australia

7 Department of Paediatrics, University of Melbourne, Melbourne, Australia

8 Language and Genetics Department, Max Planck Institute for Psycholinguistics, Nijmegen, The Netherlands

9 Donders Institute for Brain, Cognition and Behaviour, Radboud University, Nijmegen, The Netherlands

10 Department of Human Genetics, Institute for Brain, Cognition and Behaviour, Radboud University Medical Center, Nijmegen, The Netherlands 
hypotonia, facial dysmorphism; specifically upslanting palpebral fissures, epicanthal folds, a pear-shaped nose with bulbous nasal tip, and eversion of the lower lip [3, 5-7]. There is commonly central nervous system involvement of epilepsy ( $\approx 50 \%$ of individuals) and brain anomalies on MRI (e.g., corpus callosum, hydrocephalus) [6]. Co-occurring medical features include recurrent joint sublaxation, urogenital, renal, and cardiac defects, and visual deficits, such as exotropia or strabismus [6]. Cleft palate and hearing loss (conductive or sensorineural) may also occur, but are less common $[6,7]$.

Communication deficits have also been observed as part of the complex profile seen in KdVS [6, 8, 9]. Based on a limited number of case reports, expressive communication is suggested to be severely impaired in the preschool years, characterised by a striking late onset of first words (as late

Table 1 Participant developmental history and medical characteristics

\begin{tabular}{|c|c|c|c|c|c|c|c|c|c|c|c|c|}
\hline Case & $\begin{array}{l}\text { Age } \\
(\mathrm{y} ; \mathrm{m})\end{array}$ & Variant & Origin & Sex & Hypotonia & $\begin{array}{l}\text { Feeding } \\
\text { impairment }\end{array}$ & $\begin{array}{l}\text { Visual } \\
\text { impairment }\end{array}$ & Seizures & $\begin{array}{l}\text { Cognitive } \\
\text { impairment }\end{array}$ & $\begin{array}{l}\text { Speech } \\
\text { therapy }\end{array}$ & $\begin{array}{l}\text { Motor } \\
\text { apraxia/ } \\
\text { delay }\end{array}$ & $\mathrm{OT} / \mathrm{PT}$ \\
\hline 1 & $1 ; 0$ & $17 \mathrm{q} 21 \mathrm{del}$ & $\mathrm{AU}$ & $\mathrm{F}$ & $\mathrm{Y}$ & $\mathrm{Y}$ & $\mathrm{N}$ & NR & NR & $\mathrm{Y}$ & NR & $\mathrm{N}$ \\
\hline 2 & $2 ; 0$ & $17 \mathrm{q} 21 \mathrm{del}$ & US & M & $\mathrm{Y}$ & $\mathrm{Y}$ & $\mathrm{Y}$ & $\mathrm{Y}$ & NR & $\mathrm{Y}$ & $\mathrm{Y}$ & $\mathrm{Y}$ \\
\hline 3 & $2 ; 5$ & $17 \mathrm{q} 21 \mathrm{del}$ & US & $\mathrm{F}$ & $\mathrm{Y}$ & $\mathrm{Y}$ & $\mathrm{Y}$ & NR & $\mathrm{Y}$ & $\mathrm{Y}$ & $\mathrm{Y}$ & $\mathrm{Y}$ \\
\hline 4 & $2 ; 5$ & $17 \mathrm{q} 21 \mathrm{del}$ & US & $\mathrm{F}$ & $\mathrm{Y}$ & $\mathrm{Y}$ & $\mathrm{Y}$ & $\mathrm{Y}$ & NR & $\mathrm{Y}$ & $\mathrm{Y}$ & $\mathrm{N}$ \\
\hline 5 & $2 ; 7$ & $17 \mathrm{q} 21 \mathrm{del}$ & $\mathrm{AU}$ & $\mathrm{F}$ & NR & NR & $\mathrm{N}$ & NR & NR & $\mathrm{Y}$ & $\mathrm{Y}$ & $\mathrm{N}$ \\
\hline 6 & $2 ; 9$ & $17 \mathrm{q} 21 \mathrm{del}$ & $\mathrm{AU}$ & M & $\mathrm{Y}$ & NR & $\mathrm{N}$ & $\mathrm{Y}$ & NR & $\mathrm{Y}$ & NR & $\mathrm{N}$ \\
\hline 7 & $3 ; 0$ & $17 \mathrm{q} 21 \mathrm{del}$ & $\mathrm{NZ}$ & M & $\mathrm{Y}$ & $\mathrm{Y}$ & $\mathrm{N}$ & $\mathrm{Y}$ & NR & $\mathrm{Y}$ & $\mathrm{Y}$ & $\mathrm{N}$ \\
\hline 8 & $3 ; 1$ & $17 \mathrm{q} 21 \mathrm{del}$ & $\mathrm{AU}$ & M & $\mathrm{Y}$ & $\mathrm{Y}$ & $\mathrm{a}$ & $\mathrm{Y}$ & $\mathrm{Y}$ & $\mathrm{Y}$ & $\mathrm{Y}$ & $\mathrm{Y}$ \\
\hline 9 & $3 ; 4$ & $17 \mathrm{q} 21 \mathrm{del}$ & $\mathrm{AU}$ & $\mathrm{F}$ & NR & NR & $\mathrm{N}$ & $\mathrm{Y}$ & NR & $\mathrm{Y}$ & NR & $\mathrm{Y}$ \\
\hline 10 & $3 ; 7$ & $17 \mathrm{q} 21 \mathrm{del}$ & US & M & NR & $\mathrm{Y}$ & $\mathrm{N}$ & NR & NR & $\mathrm{Y}$ & NR & $\mathrm{Y}$ \\
\hline 11 & $3 ; 8$ & $17 \mathrm{q} 21 \mathrm{del}$ & US & $\mathrm{F}$ & $\mathrm{Y}$ & $\mathrm{Y}$ & $\mathrm{Y}$ & $\mathrm{N}$ & NR & $\mathrm{Y}$ & $\mathrm{Y}$ & $\mathrm{Y}$ \\
\hline 12 & $4 ; 8$ & $17 q 21 \mathrm{del}$ & Brazil & M & $\mathrm{Y}$ & $\mathrm{Y}$ & $\mathrm{N}$ & $\mathrm{Y}$ & $\mathrm{Y}$ & $\mathrm{Y}$ & $\mathrm{Y}$ & $\mathrm{Y}$ \\
\hline 13 & $4 ; 11$ & $17 q 21 \mathrm{del}$ & $\mathrm{AU}$ & $\mathrm{F}$ & $\mathrm{Y}$ & $\mathrm{Y}$ & $\mathrm{N}$ & $\mathrm{Y}$ & NR & $\mathrm{Y}$ & $\mathrm{Y}$ & $\mathrm{Y}$ \\
\hline 14 & $5 ; 6$ & $17 q 21 \mathrm{del}$ & US & $\mathrm{F}$ & NR & NR & $\mathrm{N}$ & NR & NR & $\mathrm{Y}$ & NR & $\mathrm{Y}$ \\
\hline 15 & $5 ; 8$ & $17 \mathrm{q} 21 \mathrm{del}$ & US & $\mathrm{F}$ & $\mathrm{Y}$ & $\mathrm{Y}$ & $\mathrm{N}$ & $\mathrm{Y}$ & $\mathrm{Y}$ & $\mathrm{Y}$ & $\mathrm{Y}$ & $\mathrm{Y}$ \\
\hline 16 & $7 ; 3$ & $\begin{array}{l}\text { c.531_540del, p. } \\
\text { (Gly179Leufs) }\end{array}$ & US & $\mathrm{F}$ & $\mathrm{Y}$ & $\mathrm{Y}$ & $\mathrm{Y}$ & $\mathrm{Y}$ & $\mathrm{Y}$ & $\mathrm{Y}$ & $\mathrm{Y}$ & $\mathrm{Y}$ \\
\hline 17 & $9 ; 0$ & $17 \mathrm{q} 21 \mathrm{del}$ & US & M & $\mathrm{Y}$ & NR & $\mathrm{N}$ & NR & $\mathrm{Y}$ & $\mathrm{Y}$ & $\mathrm{Y}$ & $\mathrm{N}$ \\
\hline 18 & $9 ; 11$ & $17 \mathrm{q} 21 \mathrm{del}$ & US & M & $\mathrm{Y}$ & $\mathrm{Y}$ & $\mathrm{N}$ & $\mathrm{Y}$ & $\mathrm{Y}$ & $\mathrm{Y}$ & $\mathrm{Y}$ & $\mathrm{Y}$ \\
\hline 19 & $10 ; 6$ & $\begin{array}{l}\text { c. } 1816 C>T, p . \\
\text { (Arg606Ter) }\end{array}$ & US & $\mathrm{F}$ & $\mathrm{Y}$ & $\mathrm{Y}$ & $\mathrm{Y}$ & $\mathrm{Y}$ & $\mathrm{N}$ & $\mathrm{Y}$ & $\mathrm{Y}$ & $\mathrm{Y}$ \\
\hline 20 & $10 ; 10$ & $17 \mathrm{q} 21 \mathrm{del}$ & US & M & $\mathrm{Y}$ & $\mathrm{Y}$ & $\mathrm{N}$ & $\mathrm{Y}$ & $\mathrm{N}$ & $\mathrm{Y}$ & $\mathrm{Y}$ & $\mathrm{Y}$ \\
\hline 21 & $11 ; 7$ & $17 \mathrm{q} 21 \mathrm{del}$ & US & $\mathrm{F}$ & $\mathrm{Y}$ & $\mathrm{Y}$ & $\mathrm{N}$ & NR & $\mathrm{Y}$ & $\mathrm{Y}$ & $\mathrm{Y}$ & $\mathrm{Y}$ \\
\hline 22 & $12 ; 3$ & $17 \mathrm{q} 21 \mathrm{del}$ & $\mathrm{AU}$ & $\mathrm{F}$ & $\mathrm{Y}$ & $\mathrm{Y}$ & $\mathrm{Y}$ & $\mathrm{Y}$ & $\mathrm{Y}$ & $\mathrm{N}$ & $\mathrm{Y}$ & $\mathrm{N}$ \\
\hline 23 & $12 ; 5$ & $\begin{array}{l}\text { c.2699_2702dup, } \\
\text { p.(Ser901Argfs) }\end{array}$ & Nederlands & M & $\mathrm{Y}$ & $\mathrm{Y}$ & $\mathrm{Y}$ & $\mathrm{Y}$ & $\mathrm{Y}$ & $\mathrm{Y}$ & $\mathrm{Y}$ & $\mathrm{Y}$ \\
\hline 24 & $12 ; 8$ & $17 \mathrm{q} 21 \mathrm{del}$ & $\mathrm{AU}$ & M & NR & NR & $\mathrm{N}$ & $\mathrm{Y}$ & $\mathrm{Y}$ & $\mathrm{Y}$ & NR & $\mathrm{N}$ \\
\hline 25 & $15 ; 6$ & $17 q 21 \mathrm{del}$ & Nederlands & $\mathrm{F}$ & $\mathrm{Y}$ & $\mathrm{Y}$ & $\mathrm{Y}$ & $\mathrm{N}$ & $\mathrm{Y}$ & $\mathrm{Y}$ & $\mathrm{Y}$ & $\mathrm{Y}$ \\
\hline 26 & $16 ; 11$ & $\begin{array}{l}\text { c. } 1652+1 \mathrm{G}>\mathrm{A}, \mathrm{p} . \\
(?)\end{array}$ & Nederlands & M & Y & $\mathrm{Y}$ & $\mathrm{Y}$ & $\mathrm{N}$ & $\mathrm{Y}$ & $\mathrm{Y}$ & $\mathrm{Y}$ & NR \\
\hline 27 & $21 ; 0$ & $17 \mathrm{q} 21 \mathrm{del}$ & US & $\mathrm{F}$ & $\mathrm{Y}$ & $\mathrm{Y}$ & $\mathrm{N}$ & $\mathrm{Y}$ & $\mathrm{Y}$ & $\mathrm{N}$ & $\mathrm{Y}$ & $\mathrm{Y}$ \\
\hline 28 & $25 ; 11$ & $17 \mathrm{q} 21 \mathrm{del}$ & Nederlands & $\mathrm{F}$ & $\mathrm{Y}$ & $\mathrm{Y}$ & $\mathrm{Y}$ & $\mathrm{Y}$ & $\mathrm{Y}$ & $\mathrm{Y}$ & $\mathrm{Y}$ & $\mathrm{Y}$ \\
\hline 29 & $27 ; 0$ & $17 q 21 \mathrm{del}$ & $\mathrm{AU}$ & $\mathrm{F}$ & $\mathrm{Y}$ & $\mathrm{Y}$ & $\mathrm{Y}$ & NR & $\mathrm{Y}$ & $\mathrm{Y}$ & NR & $\mathrm{Y}$ \\
\hline
\end{tabular}

Amino-acid positions are provided according to the NM_001193466.1 transcript and the NP_001180395.1 isoform.17q21 del refers to the recurrent $\sim 600 \mathrm{~kb}$ deletion at 17q21.31, defined as chr17:g.(43582682_43868942)_(44110194_44479336)del (hg19)

$A U$ Australia, US United States, $N R$ not reported in collated health professional reports, $Y$ feature present, $N$ feature absent; Speech therapy from onset of first words to current age; $O T$ occupational therapy, $P T$ physiotherapy

${ }^{a}$ Yet to have vision tested 
as 3 years of age) and a need for therapy in both verbal and nonverbal domains (e.g., sign language, aided communication, such as computer touch screens) $[5,6,8$, 10]. Anecdotally, expressive speech and language abilities are more severely impaired than receptive language abilities or more generally, motor skills [6]. However, one study found commensurate expressive and receptive language skills in two of three young adults examined, with only one of the three having better receptive language [5].

Information about social skills in individuals with KdVS is limited. In the three adults described by Egger et al. [5], participants showed a relatively strong memory for socialcontextual information, appropriate emotion perception, less social fear, more approaching behaviour, and a high level of frustration tolerance. The authors concluded social skills were a relative strength for children with $\mathrm{KdVS}$ as also seen in Angelman (15q11-q13) and Williams-Beuren (7q11.23) syndromes. Nonetheless, social skills encompass a broad range of areas beyond those examined in KdVS cases to date, including pragmatic language abilities of initiation, nonverbal communication, social relations, interests, and context. An evaluation of pragmatic social language abilities has not yet been carried out in a cohort with KdVS, and as such it remains unknown whether features of autism spectrum disorder (ASD) are associated with the syndrome.

As elucidated here, current evidence for the communication phenotype associated with KdVS is based on case studies only. There has been no cohort study in this field, limiting understanding of homogeneity of phenotype and features most closely associated with KANSL1. Further, there has been no systematic examination of specific diagnoses or severity of involvement across speech (e.g., articulation, dysarthria, apraxia), language (e.g., expressive and receptive abilities) and literacy (e.g., reading and spelling profiles). The lack of a well-defined phenotype limits current prognostic counselling for speech and language outcomes in this syndrome, and prevents efficient application of targeted therapies to newly presenting affected children.

Here, we conduct the first prospective study of oralmotor, speech, language, literacy, and pragmatic social skills in a large cohort of unrelated children with $\mathrm{KdVS}$, using standardised tests normed for typical behaviour, to precisely characterise the communication phenotype associated with this syndrome.

\section{Methods}

Inclusion criteria were a confirmed diagnosis of $\mathrm{KdVS}$ (chromosome 17q21.31 microdeletion or KANSL1 variants) and aged $\geq 1 ; 0$ year (Table 1 ). Participants were ascertained via a parent support group website (http://www. supportingkdvs.com); a clinical-research website (http:// www.17q21.com/en/) relating to KdVS and Victorian Clinical Genetics Services; a statewide clinical genetics service based in Melbourne, Australia. Ethics approval for the study was obtained from the Royal Children's Hospital, Melbourne, Human Research Ethics Committee (HREC 27053).

Twenty-nine participants (12 males), aged between 1.0 and 25 years 11 months took part in the study. The majority of participants $(n=25)$ had the common $\approx 600 \mathrm{~kb}$ deletion at $17 \mathrm{q} 21.31$ [10] and the remainder of the group ( $n$ =4) had nonsense KANSL1 variants (Table 1). Children were recruited internationally (14 US, 9AU, 4 Netherlands, 1 New Zealand, 1 Brazil). Local treating speech pathology clinicians completed a pre-determined protocol examining oral motor structure and function, speech, language and pragmatic social skills functioning as outlined below. Standardised tests were administered and scored relative to normative data, in line with the respective test manuals. The same tests were used where both Dutch and English versions were available. In the absence of the same standardised speech assessments in Brazil, this child's performance across speech, language, literacy and social skills domains was reported by his local treating speech pathologist with reference to local normative data.

The $17 q 21.31$ deletions and phenotypic data were submitted to the Decipher database (https://decipher.sanger.ac. $\mathrm{uk} /$ ) and KANSL1 sequence variants and phenotypic data were submitted to the Clin Var Database (https://www.ncbi. nlm.nih.gov/clinvar/).

\section{Developmental history and co-occurring health conditions}

Data were collected on genotype (KANSL1 variant or chromosome 17q21.31 microdeletion), development (e.g., intellectual quotient, first words, feeding history, motor milestones), co-occurring medical features (e.g., laryngomalacia, hypotonia, epilepsy, neurological MRI results, hearing, vision, cleft lip/palate, dysmorphic features, renal, cardiac, urogenital), presence of neurodevelopmental conditions (e.g., ASD, attention deficit hyperactivity disorder), and type and amount of therapeutic input (e.g., speech therapy, occupational therapy) (Table 1). Data was collected from relevant health practitioner reports (e.g., clinical geneticists, audiologists, optometrists, neurologists, craniofacial specialists, speech therapists). The denominators used to determine the proportion of affected cases reflect available data. 


\section{Oral-motor}

Structural or functional impairments of the oral region were assessed with the Clinical Assessment of Oropharyngeal Motor Development in Young Children [11] for children aged $\geq 2.0$ years. This tool examines oral-facial structural integrity (e.g., symmetry, occlusion, size of facial features, height of palatal vault, dental alignment/gaps/decay) and oral motor function (e.g., seal of the lips, fasciculations/ atrophy/furrowing of the tongue, ability to retract and protrude the tongue). This tool was administered in the local language (i.e., Dutch, English, or Portugese). Oral motor structure and function performance does not vary across linguistically diverse groups. The Schedule for Oral Motor Assessment [12] examined oral motor structure and function in one participant aged $<2.0$ years.

\section{Speech measures}

The standardised Goldman-Fristoe Test of Articulation (sounds-in-words subtest and stimulability probe) (GFTA2) [13] was administered in English-speaking children with sufficient verbal production at the single world level. The Dutch-normed computer articulation instrument (CAI) was administered [14] to Dutch children. Phonological process analysis was conducted on the GFTA-2 and CAI productions to differentially diagnose articulation (movement plan and motor production of the sound) ability and phonological performance (a child's understanding of sound rules of their language) [15]. Where children had sufficient speech, a 5min conversational sample was obtained, and analysed using pre-determined cross-linguistically valid protocols for childhood apraxia of speech (CAS) [16] and dysarthria [1619].

\section{Language measures}

The Preschool Language Fundamentals-5 [20] (PLS-5), the Clinical Evaluation of Language Fundaments (CELF)-Preschool 2 [21] or CELF-IV, [22] were most commonly used to assess language; depending on age of the participant and availability of the tool for the clinician. The PLS-5, is a test of receptive and expressive language for children aged 0-7 years 11 months. Standard scores were obtained for the auditory comprehension (receptive language) and expressive communication (expressive language) subscales. The CELF-IV (age range 5-21 years) and CELF-P2 (3-6 years) also provide standardised expressive and receptive language summary scores. Dutch participants were tested with the CELF-Dutch version [23], or the Schlichting test for language comprehension and production [24] $(n=2)$. The Schlichting test also provides receptive and expressive language scores. All of the language tools described here examine similar domains and have a mean score of 100 (SD $15)$, with a score of $85-115$ representing average range performance; with language severity as follows: mild (1-1.5SD below mean), moderate (1.5-2SD below mean) and severe ( $>2 \mathrm{SD}$ below mean). One adult was assessed with the Mt. Wilga High Level Language test [25].

\section{Literacy}

The Wide Range Achievement Test-Fourth Edition (WRAT-4) word reading and spelling subtests were administered [26] to English-speaking children aged $\geq 5$ years, with standard scores (mean $=100, \mathrm{SD}=15$ ) and equivalent severity ratings as for language above [26].

\section{Social skills-pragmatic language}

The Children's Communication Checklist-Second Edition (CCC-2) Social Interaction Difference Index (age range 4-16 years) was used to examine verbal and non-verbal social communication skills [27] in Dutch and Englishspeaking children. The participant's treating speech pathologist made a subjective clinical rating on social pragmatic abilities relative to peers (appropriate/within normal limits, mildly, moderately or severely affected), where participants did not fulfil the age range for the CCC-2 or where the tool was not available. Formal diagnoses of ASD were recorded.

\section{Results}

\section{Developmental history and co-occurring health conditions}

Hypotonia was a core deficit $(n=24 / 24 ; 100 \%)$ and related to early feeding difficulties $(23 / 23,100 \%)$, tracheomalacia or laryngomalacia $(n=11 / 11 ; 100 \%)$ and gastroesophageal reflux were regularly seen $(n=9 / 11 ; 81 \%)$ (see Table 1 , Supplementary Table 1). Chewing difficulties $(n=20 / 23$; $87 \%)$ and profuse anterior drooling were common $(n=20 /$ $22 ; 91 \%)$. Drooling resolved in preschool or early school years for most $(n=9 / 20 ; 45 \%)$.

A majority $(n=22 / 22 ; 100 \%)$ had generalised motor delay or disorder due to hypotonia and/or a motor programming (praxis) deficit. Occupational and/or physiotherapy was commonly required $(n=20 / 28 ; 71 \%)$. Motor deficits included difficulties managing buttons and zippers, writing, drawing, using scissors, riding a bike and toilet training.

Non-verbal cognitive impairment (score $<85$ on standardised tools in neuropsychological reports) was common where examined $(n=16 / 18 ; 89 \%)$. Yet, few children under 
Table 2 Speech, oral motor, language, literacy and social skills

\begin{tabular}{|c|c|c|c|c|c|c|c|c|c|c|}
\hline Case & Age & Variant & Dysarthria & $\begin{array}{l}\text { Speech } \\
\text { apraxia }\end{array}$ & $\begin{array}{l}\text { Oral motor } \\
\text { impairment }\end{array}$ & $\begin{array}{l}\text { Expressive } \\
\text { language } \\
\text { impairment }\end{array}$ & $\begin{array}{l}\text { Receptive } \\
\text { language } \\
\text { impairment }\end{array}$ & $\begin{array}{l}\text { Reading } \\
\text { impairment }\end{array}$ & $\begin{array}{l}\text { Spelling } \\
\text { impairment }\end{array}$ & $\begin{array}{l}\text { Social skills } \\
\text { impairment }\end{array}$ \\
\hline 1 & $1 ; 0$ & $17 \mathrm{q} 21 \mathrm{del}$ & NA & NA & $\mathrm{Y}$ & WNL & WNL & NA & NA & WNL \\
\hline 2 & $2 ; 0$ & $17 \mathrm{q} 21 \mathrm{del}$ & $\mathrm{Y}$ & $\mathrm{Y}$ & $\mathrm{Y}$ & Severe & Severe & NA & NA & NR \\
\hline 3 & 2,5 & $17 \mathrm{q} 21 \mathrm{del}$ & NA & $\mathrm{Y}$ & $\mathrm{Y}$ & Severe & Severe & NA & NA & NR \\
\hline 4 & $2 ; 5$ & $17 \mathrm{q} 21 \mathrm{del}$ & NA & $\mathrm{Y}$ & $\mathrm{Y}$ & Mild & WNL & NA & NA & Appropriate \\
\hline 5 & $2 ; 7$ & $17 \mathrm{q} 21 \mathrm{del}$ & NA & $\mathrm{Y}$ & $\mathrm{Y}$ & Mild & Mild & NA & NA & NR \\
\hline 6 & $2 ; 9$ & $17 \mathrm{q} 21 \mathrm{del}$ & NA & $\mathrm{Y}$ & $\mathrm{Y}$ & Severe & Severe & NA & NA & Appropriate \\
\hline 7 & $3 ; 0$ & $17 q 21 \mathrm{del}$ & NA & Y & $\mathrm{Y}$ & Severe & Severe & NA & NA & WNL \\
\hline 8 & $3 ; 1$ & $17 \mathrm{q} 21 \mathrm{del}$ & Y & $\mathrm{Y}$ & $\mathrm{Y}$ & Severe & Severe & NA & NA & Mild \\
\hline 9 & $3 ; 4$ & $17 q 21 \mathrm{del}$ & $\mathrm{N}$ & $\mathrm{Y}$ & $\mathrm{Y}$ & Moderate & Mild & NA & NA & Mild \\
\hline 10 & $3 ; 7$ & $17 \mathrm{q} 21 \mathrm{del}$ & NR & $\mathrm{Y}$ & $\mathrm{Y}$ & Severe & Severe & NA & NA & WNL \\
\hline 11 & $3 ; 8$ & $17 \mathrm{q} 21 \mathrm{del}$ & NR & $\mathrm{Y}$ & $\mathrm{Y}$ & Mild & WNL & NA & NA & Appropriate \\
\hline 12 & $4 ; 8$ & $17 \mathrm{q} 21 \mathrm{del}$ & $\mathrm{Y}$ & NR & NR & Severe & Severe & NA & NA & Appropriate \\
\hline 13 & $4 ; 11$ & $17 \mathrm{q} 21 \mathrm{del}$ & $\mathrm{Y}$ & $\mathrm{Y}$ & $\mathrm{Y}$ & Mild & WNL & NA & NA & Moderate $^{\mathrm{a}}$ \\
\hline 14 & $5 ; 6$ & $17 \mathrm{q} 21 \mathrm{del}$ & NR & $\mathrm{Y}$ & $\mathrm{Y}$ & Severe & Severe & NA & NA & NR \\
\hline 15 & $5 ; 8$ & $17 \mathrm{q} 21 \mathrm{del}$ & NR & $\mathrm{NR}^{\mathrm{b}}$ & NR & Severe & Severe & Mild & Mild & NR \\
\hline 16 & $7 ; 3$ & $\begin{array}{l}\text { c.531_540del, p. } \\
\text { (Gly179Leufs) }\end{array}$ & Y & NR & $\mathrm{Y}$ & Moderate & Moderate & WNL & Mild & Appropriate \\
\hline 17 & $9 ; 0$ & $17 q 21 \mathrm{del}$ & Y & $\mathrm{Y}$ & $\mathrm{Y}$ & Severe & Severe & NA & NA & NR \\
\hline 18 & $9 ; 11$ & $17 q 21 \mathrm{del}$ & NR & $\mathrm{Y}$ & $\mathrm{Y}$ & Severe & Severe & NA & NA & NR \\
\hline 19 & $10 ; 6$ & $\begin{array}{l}\text { c. } 1816 C>T, p . \\
\text { (Arg606Ter) }\end{array}$ & NR & $\mathrm{Y}$ & $\mathrm{Y}$ & Severe & Severe & NA & NA & Moderate \\
\hline 20 & $10 ; 10$ & $17 q 21 \mathrm{del}$ & $\mathrm{Y}$ & $\mathrm{Y}$ & $\mathrm{Y}$ & Severe & Moderate & WNL & WNL & NR \\
\hline 21 & $11 ; 7$ & $17 q 21 \mathrm{del}$ & $\mathrm{Y}$ & $\mathrm{Y}$ & $\mathrm{Y}$ & WNL & Moderate & Mild & Severe & Appropriate \\
\hline 22 & $12 ; 3$ & $17 \mathrm{q} 21 \mathrm{del}$ & NR & $\mathrm{Y}$ & $\mathrm{Y}$ & Severe & Severe & NA & NA & Moderate $^{\mathrm{a}}$ \\
\hline 23 & $12 ; 5$ & $\begin{array}{l}\text { c.2699_2702dup, p. } \\
\text { (Ser901Argfs) }\end{array}$ & $\mathrm{Y}$ & $\mathrm{Y}$ & $\mathrm{Y}$ & Severe & Severe & NA & NA & Mild \\
\hline 24 & $12 ; 8$ & $17 q 21 \mathrm{del}$ & $\mathrm{Y}$ & $\mathrm{Y}$ & $\mathrm{Y}$ & Severe & Severe & Severe & Severe & Mild \\
\hline 25 & $15 ; 6$ & $17 q 21 \mathrm{del}$ & $\mathrm{Y}$ & $\mathrm{Y}$ & $\mathrm{Y}$ & Severe & Severe & NA & NA & Mild \\
\hline 26 & $16 ; 11$ & $\begin{array}{l}\text { c. } 1652+1 \mathrm{G}>\mathrm{A}, \mathrm{p} . \\
(?)\end{array}$ & $\mathrm{Y}$ & $\mathrm{Y}$ & $\mathrm{Y}$ & Severe & Severe & NA & NA & Severe $^{\mathrm{a}}$ \\
\hline 27 & $21 ; 0$ & $17 q 21 \mathrm{del}$ & NR & NR & NR & Severe & Severe & Severe & Moderate & Moderate \\
\hline 28 & $25 ; 11$ & $17 q 21 \mathrm{del}$ & Y & $\mathrm{Y}$ & $\mathrm{Y}$ & Severe & Severe & NA & NA & Moderate \\
\hline 29 & $27 ; 0$ & $17 \mathrm{q} 21 \mathrm{del}$ & $\mathrm{Y}$ & $\mathrm{Y}$ & $\mathrm{Y}$ & Severe & Severe & Severe & Severe & Moderate \\
\hline
\end{tabular}

$N R$ not reported by local speech pathologist or collated health professional reports, $N A$ not assessed as not developmentally appropriate or not able to be tested, $W N L$ within normal limits, $Y$ feature present

${ }^{a}$ Autistic traits

${ }^{\mathrm{b}}$ Childhood apraxia of speech not reported, but child not using 3-5 word phrases, dropping plurals and word endings, nasal errors, inconsistent speech errors

the age of 5 years $(3 / 13)$ had received cognitive examinations. Seizures were common $(18 / 21,86 \%)$ and epilepsy confirmed via electroencephalogram in two-thirds of these cases $(10 / 18 ; 55 \%)$. Hearing impairment included mild and mild-moderate sensorineural deafness (ID 18, $n=1 / 29$; $3 \%$ ), and periodic conductive loss associated with otitis media $(n=4 / 29 ; 14 \%)$. All participants with visual impairments wore glasses $(n=12 / 28 ; 43 \%)$ and strabismus was the most common diagnosis. Features seen in only one participant were: hypothyroidism, congenital heart defect, which resolved by 2 years of age; a tethered spinal cord with sacral sinus; malignant melanoma of the forearm; and hepatic dysfunction alongside hypoglycemia and ketosis.

Academically, seven participants $(7 / 18,39 \%)$ attended mainstream schools. The remaining $11(61 \%)$ attended special schools. This proportion is likely influenced by the 
geographical location of the family (i.e., whether the region supported mainstream schooling or separate special schools), not only the individual child's abilities.

First words were delayed in all but three children, who had appropriate onset of first words at 12 and 13 months, respectively. Most had first words between ages 2.5 and 3.5 years, with two individuals having onset delayed until 5 and 7 years, respectively. All but two $(n=26 / 28,93 \%)$ had received regular speech therapy from the onset of first words until the time of this study, with increased intensity in the preschool period (typically once per week or fortnight, but as much as twice per week where it could be afforded).

\section{Communication phenotype}

\section{Oral-motor}

Three individuals had cleft lip and palate (ID 15, 18, 26). Hypodontia $(n=7 / 7 ; 100 \%)$, macroglossia $(n=5 / 12 ; 42 \%)$ and malocclusion (cross-bite or underbite) $(n=8 / 13 ; 62 \%)$ were noted in a subset of participants. High arch palate was reported in half of the group $(n=8 / 16,50 \%)$ (Supplementary Table 1).

Abnormal oral-motor function deficits were evident in all participants assessed ( $n=26 / 26,100 \%$ ) to some degree. Specifically, reduced range and precision of single mandibular, labial-facial, laryngeal and lingual movements was noted (e.g., poke out your tongue; blow a kiss). Praxis deficits were equally common across more complex multimovement non-speech oral and speech sequences.

\section{Speech}

The most common speech diagnosis was CAS (speech apraxia) ( $n=24 / 24,100 \%$ ) (Table 2 ). The speech profile was characterised by exceptionally delayed onset of first words, limited babbling, reduced phonetic inventories (i.e., had not acquired all English sounds) relative to typical peers, more errors on vowels than consonants, inconsistency of errors, addition and omission errors in attempts to simplify syllable structures including cluster reduction, simplified syllable structures relative to age, and prosodic errors. Instances of dysfluency (stuttering), manifesting as syllable, word or phrase level repetitions, were seen in some participants $(n=3 / 18 ; 17 \%)$. A proportion $(n=14 / 15$; 93\%) had dysarthria, typically characterised by low pitch, hypernasality, monotonous, monoloud and flaccid, slow speech.

Four children (IDs 1-3,29) had few spoken words at assessment, relying on alternative forms of communication such as gesture, Makaton sign and technological supports, such as iPads to support expressive speech and language. The remaining 25 children assessed on single word performance demonstrated articulation (phonetic distortion) errors. Delayed (i.e., e.g., 'stopping' d for th in feader for feather) or atypical (i.e., sound preference substitution) phonological speech sound processes were also present across this group. All the 25 children were reported to have used early sign language, non-verbal gestures or communication devices to supplement or facilitate communication prior to intelligible speech development. Intelligible speech was obtained only after explicit teaching of sound imitation, syllable generation, syllable combinations, increasingly complex words, short phrases, sentences and spontaneous speech. Each stage required extensive work to acquire each skill and significant ongoing follow-up work to maintain the skill. Therapeutic focus emphasised language and literacy at mid-to-late school age, once speech was intelligible and children could fluently produce phrases or sentences. Frequency of speech therapy reduced, however, once children had acquired intelligible speech.

\section{Language}

Expressive and receptive language abilities were commensurate in most participants $(n=23 / 29 ; 79 \%)$. In a small subset, expressive performance was lower than receptive ( $n$ $=5 / 29 ; 17 \%)$ or vice versa $(n=1 / 29 ; 3 \%)$. Further reliable comparison across linguistic subdomains (e.g., semantics, morphology, syntax) was not possible given the range of tools used to assess language that differed in items elicited across domains, and due to the broad chronological and developmental age range examined. Language abilities were noted as commensurate with cognition by the treating clinicians. There was no clear distinction in language performance in individuals with and without seizures (Tables 1 and 2).

\section{Literacy}

Almost half the cohort $(n=13 / 29 ; 45 \%)$ were too young ( $<5$ years) for literacy testing. Testing was not conducted in a further subset determined as developmentally premature for literacy assessment $(n=6 / 29 ; 21 \%)$ or where the clinician did not have access to the WRAT assessment $(n=3$ / $29 ; 10 \%)$. Both reading and spelling performance was variable in the seven individuals assessed (Table 2). All children with typical or mildly impaired reading skills were school-aged. Two of the three individuals with more severely affected reading, relative to peers, were adults (aged 21, 27 years, respectively).

\section{Social skills-pragmatic language}

Only 5/29 (17\%) children underwent formalised testing with the CCC-2. Sixteen reports were based on subjective 
clinician judgement and data were absent for $8 / 29$ (27\%) individuals. A range of abilities were reported (Table 2). Autistic traits were seen in few participants $(n=3 / 19$, $16 \%$ ). Traits included sensory skill deficits and the need to follow a consistent routine. No child had a confirmed ASD diagnosis. Overall, children had a keen desire to communicate, good initiation, appropriate turn-taking and intact basic social skills of eye contact and non-verbal gestures. Whilst available data were limited, a widening gap in social skills relative to peers with increasing age was observed (Table 2).

\section{Discussion}

Our linguistic phenotyping in a genetically confirmed cohort with KdVS revealed a distinctive communication profile. The most striking feature was the presence of CAS and delayed onset of first words. There was no evidence for better receptive than expressive language. Literacy was commonly impaired and social pragmatic skills were varied. Whilst children have a keen desire to communicate with appropriate eye contact, turn-taking, and non-verbal gestures, higher-level pragmatic language deficits were identified in a subset of the cohort. With only four participants with nonsense intragenic KANSL1 variants, we are unable to draw definitive genotype-phenotype conclusions, yet no striking communication differences were seen between individuals with intragenic KANSL1 variants vs. those with the standard $17 \mathrm{q} 21.31$ microdeletion, in line with previous reports [6]. Group performance and treatment indications for each domain of communication are discussed below.

\section{Oral-motor}

Oral-motor dysfunction was pervasive and impacted by both hypotonia and oral praxis. Early feeding issues were influenced differentially across the group by laryngomalacia or tracheomalacia, weak suck due to hypotonia, gastroesophageal reflux generating negative food associations, and poor lip seal due to malocclusion. Drooling was influenced by the degree of hypotonia and presence of macroglossia/malocclusion and would benefit from specific therapies [28].

Chewing delays in managing solid or lumpy textures was also influenced by hypotonia, oral-motor praxis, and the presence of reflux causing negative food associations and food refusal. The delayed trajectory of feeding milestones may lead to some children with KdVS missing the 'critical period' for chewing practice or learning to manage solids [29] as seen in other neurodevelopmental conditions [30]. Focused oral feeding interventions could mitigate these issues [31, 32].

\section{Speech: CAS, dysarthria, articulation and phonological disorder}

Speech development was the core challenge in the preschool period. Almost all had CAS, often with flaccid dysarthria, and additional articulation and phonological errors. The presence of CAS with co-occurring speech diagnoses is seen in other syndromes, such as $16 \mathrm{p} 11.2$ deletion syndrome [16], Floating Harbour Syndrome [33] and 7q11.23 duplication syndrome [34]; although the speech profile in KdVS is arguably more severe by comparison, particularly in the early years. Whether this profile is underpinned by exceptionally delayed myelination or other factors is yet to be determined. Impairment of the broader motor system in KdVS, and/or deficits of the corpus callosum impacting on inter-hemisphere communication are likely factors restricting neuroplasticity and contributing to the protracted period of speech motor development. Yet there is a remarkable ongoing propensity for speech learning, and intelligible speech is acquired by the middle school years. The sociable nature of the children, with their strong desire to communicate and high tolerance for frustration [5] are positive indicators for continuing to practice speech and achieve functional outcomes. This is in contrast to other conditions, where children initiate conversation less frequently (e.g., cerebral palsy [35]) and where speech may plateau at lower levels of achievement at a younger age.

The priority for clinical management of communication in individuals with KdVS is to manage co-morbidities that may impact speech and language (e.g., optimising hearing, controlling epilepsy, repair of cleft palate and corrected malocclusion). For speech-specific intervention in children younger than 3 years of age with few words, a Core Vocabulary treatment programme could be a suitable approach [36, 37]. For children from 4 years of age with CAS, RCT-supported evidence exists for the Nuffield Dyspraxia Programme Version 3 and the Rapid Syllable Repetition programme, although these therapies have not been trialled in children with ID [38]. As apraxia resolves and children begin to acquire fluent, consistently intelligible speech, dysarthric features become more apparent and targeted dysarthria treatments may be indicated [39].

\section{Language}

Receptive and expressive language abilities were typically commensurate and severely affected in our cohort, in agreement with a previous report [5]. A lack of data on severity of non-verbal cognition precluded reliable correlational analyses between language and cognitive functioning here. No pattern of relative strengths and weaknesses in language domains was noted (i.e., across semantics, morphology and syntax). With a dearth of 
language intervention research in other genetic syndromes, let alone KdVS, selection of approaches to trial will likely be guided by intervention studies in the general developmental language disorder literature [40-42].

\section{Literacy}

The range of reading and spelling abilities seen here are likely the result of differential impairments across skills contributing to literacy, including: impacts of speech sound disorder and language impairment on phonological awareness for literacy; reduced phonological awareness skills due to frequent otitis media [43] and sensorineural hearing impairments [44]; motor praxis issues, which may impact on written spelling; and the high prevalence of visual deficits with impacts on visual integration and/or visuo-motor integration for reading and written spelling. Targeted assessment of sound awareness by a speech pathologist, visual ability by an optometrist and visual-integration for literacy by an occupational therapist is critical to tailor an intervention programme appropriate to the individual child. A therapeutic goal-setting challenge will be optimising early precursors to literacy alongside the goal of obtaining fluent, intelligible speech.

\section{Social skills}

Individuals with KdVS have been reported as "hypersociable' due to their desire to communicate [5]. Indeed our cohort had strengths in initiation of communication, desire to communicate, appropriate eye contact, non-verbal skills and turn-taking. No child had a formal diagnosis of autism and few had autistic traits. Overall, data support prior observations [5] that, relative to many genetic intellectual disability syndromes, social skills are a strength in KdVS. Here we extend the social phenotype, demonstrating challenges in narrative/story telling and in providing contextual information. Greater linguistic sophistication is required in social interactions with age, and whilst preliminary, data showed a trend for greater pragmatic impairment with increasing age. Intervention focused on narrative storytelling [45] and provision of context may support limitations in this area.

\section{Limitations and future directions}

Speech, oral-motor and language functioning was thoroughly characterised here, using a consistent approach. By contrast, few children were formally assessed for literacy or pragmatic skills. Almost half our cohort was aged $<5$ years of age, meaning it was inappropriate to measure reading and spelling development. Further, our method of using local clinicians to acquire data was limited in that many therapists did not have access to the literacy or social pragmatic tools specified in our a-priori designed protocol, despite attempts to use universally adapted tools. Nevertheless, our preliminary data will support hypothesis generation for future larger-scale studies in this area. Recruitment bias was also possible in our study that invited participants to take part in a 'speech and language examination', potentially leading to over-estimations of communication deficits in our cohort.

\section{Clinical indications summary}

Children with KdVS should be enroled in speech therapy programmes early in life, in particular with an emphasis on the acquisition of receptive and expressive language alongside tackling the motor programming and motor planning deficits associated with speech apraxia. Implementation of multi-modal communication, such as sign language or communication devices would support language acquisition and social communication development prior to fluent speech developing. Further, therapy should target not only on speech sound production in the early years, but also the understanding of sounds and ability to visually process written text to provide an optimal foundation for reading and spelling development. Finally, narrative language therapy is indicated as developmentally appropriate, to support acquisition of more sophisticated pragmatic language skills.

Acknowledgements Thanks to the families and clinicians who took part in this project. A special thanks to Mark Mitchell for considering feedback. A.M. is supported by a National Health and Medical Research Council (NHMRC) Practitioner Fellowship \#1105008. This work is also supported by the NHMRC Centre of Research Excellence in Speech and Language NeurobioloGy (CRE-SLANG) \#1116976 and NHMRC Project grant \#APP1127144, awarded to A.M., S.F. This work is also supported by the Victorian Government's Operational Infrastructure Support Programme.

Author contributions A.M., D.K. and S.F. conceived and designed the work; A.M., L.H., K.H., C.E., C.M. and D.K. acquired the data; A.M. drafted the manuscript; all authors contributed to interpretation and revision of the manuscript and approved the final version for submission.

\section{Compliance with ethical standards}

Conflict of interest The authors declare that they have no competing interests.

\section{References}

1. Koolen DA, Vissers LE, Pfundt R, et al. A new chromosome $17 \mathrm{q} 21.31$ microdeletion syndrome associated with a common inversion polymorphism. Nat Genet 2006;38:999-1001.

2. Koolen DA, Sharp AJ, Hurst JA, et al. Clinical and molecular deleniation of the $17 \mathrm{q} 21.31$ microdeletion syndrome. J Med Genet 2008;45:710-20. 
3. Koolen DA, Kramer JM, Neveling K, et al. Mutations in the chromatin modifier gene KANSL1 cause the 17q21.31 microdeletion syndrome. Nat Genet 2012;44:639-41.

4. Zollino M, Marangi G, Ponzi E, et al. Intragenic KANSL1 mutations and chromosome $17 \mathrm{q} 21.31$ deletions: broadening the clinical spectrum and genotype-phenotype correlations in a large cohort of patients. J Med Genet 2015;52:804-14.

5. Egger JIM, Wingbermuhle WMA, Verhoeven WMA, et al. Hypersociability in the behavioral phenotype of $17 \mathrm{q} 21.31$ microdeletion syndrome. Am J Med Gen Part A 2013;161A:21-6.

6. Koolen DA, Koolen DA, Pfundt R, et al. The Koolen-de Vries syndrome: a phenotypic comparison of patients with a $17 \mathrm{q} 21.31$ microdeletion versus a KANSL1 sequence variant. Eur J Hum Genet 2016;24:652-9.

7. Tan TY, Aftimos S, Worgan L, et al. Phenotypic expansion and further characterisation of the $17 \mathrm{q} 21.31$ microdeletion syndrome. J Med Genet 2009;46:480-9.

8. Bernardo P, Madia F, Santulli L, et al. 17q21.31 microdeletion syndrome: description of a case further contributing to the delineation of Koolen-de Vries syndrome. Brain Dev 2016;38:663-8.

9. Keen C, Samango-Sprouse C, Dubbs H, Zackai EH. 10-year-old female with intragenic KANSL1 mutation, no KANSL1-related intellectual disability, and preserved verbal intelligence. Am J Med Genet A 2017;173:762-765.

10. Koolen DA, de Vries BBA. KANSL1-related intellectual disability syndrome. In: Pagon RA, Adam MP, Ardinger HH, et al., editors. GeneReviews $₫$ [internet]. Seattle: University of Washington; 1993-2017, 2010 (updated 10 January 2013).

11 Robbins J, Klee T. Clinical assessment of oropharyngeal motor development in young children. $J$ Speech Hear Disord 1987;52:271-7.

12 Reilly S, Skuse D, Wolke D. Schedule for oral motor assessment. London, UK: Wiley; 1999.

13 Goldman R, Fristoe M. Goldman-Fristoe test of articulation. 2nd ed. Bloomington, MN: Pearson; 2000.

14 Maassen B, van Haaften L, Diepeveen S, et al. Computer articulation instrument. Amsterdam: Boom Uitgevers; 2017 (in press).

15 Dodd B, Morgan A (2017) Intervention case studies of child speech impairment. J\&R Press, London, UK.

16 Fedorenko E, Morgan A, Murray E, et al. A highly penetrant form of childhood apraxia of speech due to deletion of 16p11.2. Eur $\mathrm{J}$ Hum Genet 2016;24:302-6.

17 Morgan AT, Liégeois F. Re-thinking diagnostic classification of the dysarthrias: a developmental perspective. Folia Phoniatr Logop 2010;62:120-6.

18 Morgan AT, Liégeois F, Liederkerke C, et al. Role of cerebellum in fine speech control in childhood: persistent dysarthria after surgical treatment for posterior fossa tumour. Brain Lang 2011;117:69-76.

19 Morgan AT, Mei C, Da Costa A, et al. Speech and language in a genotyped cohort of individuals with Kabuki syndrome. Am J Med Genet Part A 2015;167:1483-92.

20 Zimmerman IL, Steiner VG, Pond RE. Preschool language scales: Australian and New Zealand language adapted edition. 5th ed. Sydney: Pearson; 2011.

21 Wiig EH, Secord WA, Semel E. Clinical evaluation of language fundamentals-preschool: Australian standardised edition. 2nd ed. Sydney: Harcourt Assessment; 2006.

22 Semel E, Wiig EH, Secord WA. Clinical evaluation of language fundamentals: Australian standardised edition. 4th ed. Sydney: Pearson; 2003.

23 Kort W, Schittekatte M, Compaan E. CELF-4-NL: clinical evaluation of language fundamentals. Amsterdam: Pearson Assessment and Information B.V; 2008.

24 Schlichting JEPT, Lutje Spelberg HC. Schlichting Test voor Taalproductie-II. Houten: Bohn, Stafleu van Loghum; 2010.
25 Christie J, Clark W, Mortensen L. Mt. Wilga higher level language assessment. Sydney: Speech Pathology Department, Mount Wilga Rehabilitation Centre; 1986.

26 Wilkinson GS, Robertson GJ. Wide range achievement test. 4th ed. Lutz: Psychological Assessment Resources; 2006.

27 Bishop D. Children's communication checklist. 2nd ed. Sydney: Pearson; 2003.

28 American Academy for Cerebral Palsy and Developmental Medicine (AACPDM). Sialorrhea. AACPDM, Milwaukee, WI, 2016. https://www.aacpdm.org/UserFiles/file/care-pathways-sialorrheaprint.pdf. Accessed 8 Feb 2017.

29 Fujishita A, Koga Y, Utsumi D, Nakamura A, Yoshimi T, Yoshida $\mathrm{N}$. Effects of feeding a soft diet and subsequent rehabilitation on the development of the masticatory function. J Oral Rehabil 2015;42:266-74.

30 Sanchez K, Spittle AJ, Slattery JM, Morgan AT. Oromotor feeding in children born before 30 weeks' gestation and term-born peers at 12 months' corrected age. J Pediatr 2016;178:113-8.e1.

31 van den Engel-Hoek L, van Hulst KC, van Gerven MH, van Haaften L, de Groot SA. Development of oral motor behavior related to the skill assisted spoon feeding. Infant Behav Dev 2014;37:187-91.

32 Volkert VM, Piazza CC, Vaz PC, Frese J. A pilot study to increase chewing in children with feeding disorders. Behav Modif 2013;37:391-408.

33 White SM, Morgan A, Da Costa A, et al. The phenotype of Floating-Harbor syndrome in 10 patients. Am J Med Genet A 2010;152A:821-9.

34 Mervis CB, Morris CA, Klein-Tasman BP, Velleman SL, Osborne LR 7q11.23 duplication syndrome. In: Pagon RA, Adam MP, Ardinger $\mathrm{HH}$, et al., editors. GeneReviews ${ }^{\circledR}$ [internet]. Seattle, WA: University of Washington; 1993-2017, 2015.

35 Pennington L, McConachie H. Mother-child interaction revisited: communication with non-speaking physically disabled children. Int J Lang Commun Disord 1999;34:391-416.

36 Iuzzini J, Forrest K. Evaluation of a combined treatment approach for childhood apraxia of speech. Clin Linguist Phon 2010;24:335-45.

37 Crosbie S, Holm A, Dodd B. Intervention for children with severe speech disorder: a comparison of two approaches. Int J Lang Commun Disord 2005;40:467-91.

38 Murray E, McCabe P, Ballard KJ. A randomized controlled trial for children with childhood apraxia of speech comparing rapid syllable transition treatment and the Nuffield Dyspraxia Programme-Third Edition. J Speech Lang Hear Res 2015;58:669-86.

39 Pennington L, Parker NK, Kelly H, Miller N. Speech therapy for children with dysarthria acquired before three years of age. Cochrane Database Syst Rev 2016;7:CD006937.

40 Law J, Garrett Z, Nye C. Speech and language therapy interventions for children with primary speech and language delay or disorder. Cochrane Database Syst Rev 2003;3:CD004110.

41 Bishop DV, Snowling MJ, Thompson PA, Greenhalgh T, CATALISE: A Multinational and Multidisciplinary Delphi Consensus Study. Identifying language impairments in children. PLoS One. 2016;11:e0158753

42 Bishop DV, Snowling MJ, Thompson PA, Greenhalgh T. CATALISE: a multinational and multidisciplinary Delphi consensus study of problems with language development. Phase 2. Terminology. Peer J 2016;4:e2484v1.

43 Winskell $\mathrm{H}$. The effects of an early history of otitis media on children's language and literacy skill development. Br J Educ Psychol 2006;76:727-44.

44 Park J, Lombardino LJ, Ritter M. Phonology matters: a comprehensive investigation of reading and spelling skills of school-age 
children with mild to moderate sensorineural hearing loss. Am Ann Deaf 2013;158:20-40.

45 Adams C, Lockton E, Freed J, et al. The Social Communication Intervention Project: a randomized controlled trial of the effectiveness of speech and language therapy for school-age children who have pragmatic and social communication problems with or without autism spectrum disorder. Int J Lang Commun Disord 2012;47:233-44. 